\title{
KEY INITIATIVES TO ACHIEVE HEALTH GAIN FOR CHILDREN
}

\section{Victor Nossar}

Service Director, Department of Community Paediatrics, South Western Sydney Area Health Service

\section{Garth Alperstein}

Community Paediatrician, Community Health Services, Central Sydney Area Health Service

This article describes the way key population-based interventions, carried out at the appropriate stage of life, can result in better health outcomes for children.

In general, the health literature focuses on interventions that, although important, benefit relatively few children. If, however, the position of achieving the maximum health gain for the most children is taken, one is compelled to look at very different problems requiring very different interventions.

Analysis of the literature describing the efficacy of programs and interventions to achieve health gain for populations of children reveals relatively few that are capable of making significant contributions. However, when these key interventions are mapped against the life stages of children, they offer a blueprint for the greatest health gains for the greatest number of children (Figure 2). ${ }^{1}$
Some of these initiatives, such as home visiting programs, early intervention programs and health promoting schools (in the context of a settings approach to health problems) have been described in more detail in this series. ${ }^{2-4}$ The cost-benefits of breastfeeding, immunisation and cessation or prevention of tobacco smoking are well established and extensively documented. ${ }^{5-7}$ The educational status of parents, particularly mothers, is associated with improved health outcomes, including reductions in infant and child mortality. ${ }^{8}$ One of the most effective components of the Positive Parenting Program (Triple P) is a population-based behavioural family intervention program for preschool children. ${ }^{9}$

The social and physical environment, political influences, and economic status can also significantly affect the health of communities. Health workers have an obligation to advocate improvements to these important determinants of health status.

When considered together, these programs indicate the critical interventions required, in the various stages of children's lives, to achieve maximum improvement in the health of most children. This population-based perspective on child health thus represents a counterpoint to the dominant focus, the care of sick or injured children, which

FIGURE 2

\section{KEY INTERVENTIONS FOR IMPROVING THE HEALTH OF CHILDREN}

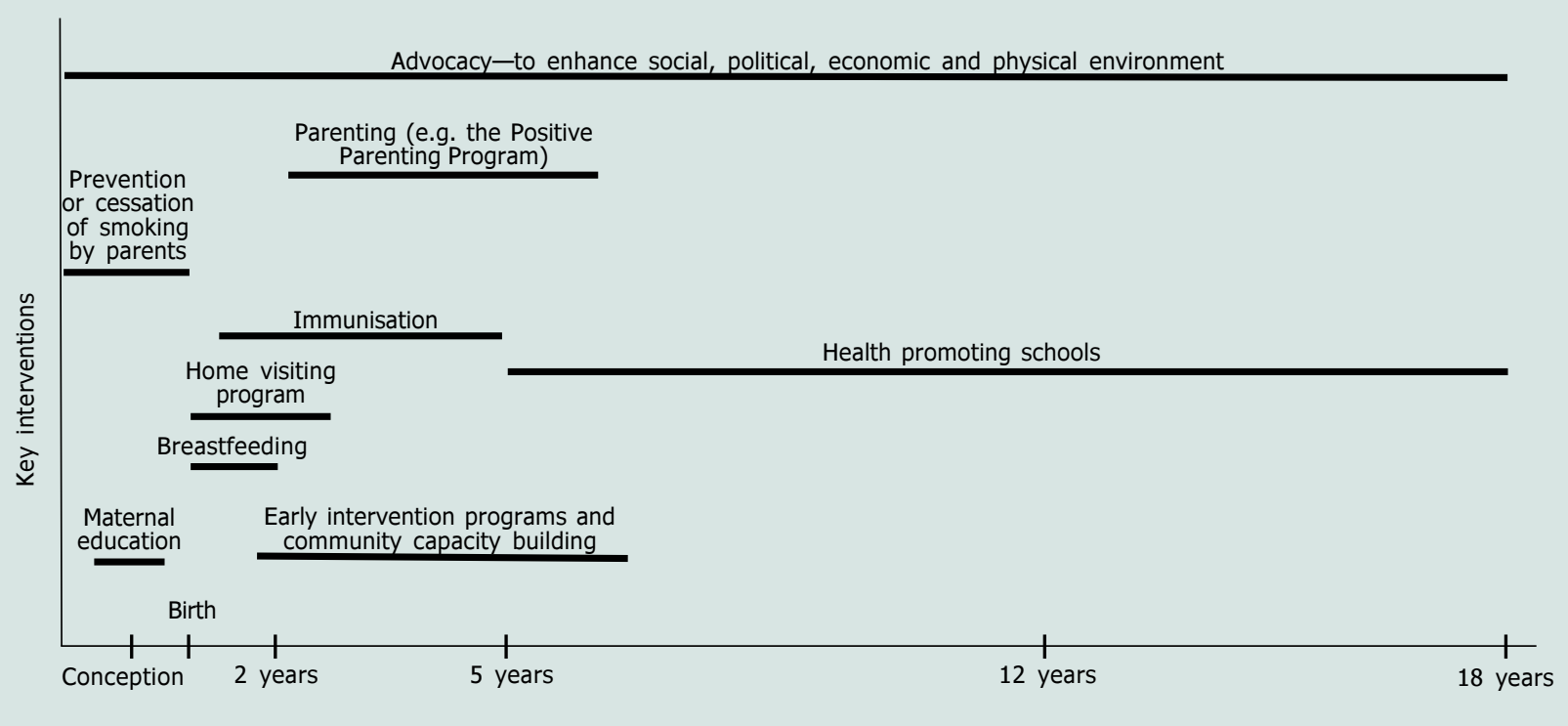

Age of child 
alone is unable to significantly influence the principal determinants of children's health.

\section{REFERENCES}

1. Achieving health outcomes for children in NSWstrengthening families and communities. Draft discussion paper. Sydney: Policy Division, Health Services Policy Branch, NSW Health Department, 1998.

2. Pope S, Raphael B. Improving the health of children in NSW: mental health issues for children. NSW Public Health Bulletin 1998; 9(10): 114-117.

3. Vimpani G. Home visiting: an essential building block to support families. NSW Public Health Bulletin 1998; 9(11): 129.

4. King L. The settings approach to achieving better health for children. NSW Public Health Bulletin 1998; 9(11): 127.

5. Montgomery DL, Splett PL. Economic benefit of breastfeeding infants enrolled in WIC. J Am Diet Assoc 1997; 97 : 379-385.

6. McIntyre P, Hall J, Leeder S. Economic analysis of childhood immunisation against Haemophilus influenzae type b disease. Aust J Public Health 1994; 18: 394-400.

7. Aligne A, Stoddard JJ. Tobacco and children - an economic evaluation of the medical effects of parental smoking. Arch Pediatr Adolesc Med 1997; 151: 648-653.

8. Cleland J, Ginnekin J. The effect of maternal schooling on child mortality: the search for an explanation. Health intervention and mortality change in developing countries. Conference, University of Sheffield, 9-11 September, 1987.

9. Sanders MR, Markie-Dodds C. Toward a technology of prevention of disruptive behaviour disorders: the role of behavioural family intervention. Behav Change 1992; 9: 186200. w

\section{CHANGE TO THE MMR SCHEDULE AND THE NSW HEALTH DEPARTMENT IMMUNISATION CERTIFICATE FOR PRIMARY SCHOOL ENTRY}

On 8 July 1998, the National Health and Medical Research Council (NHMRC) recommended a revised schedule for the measles, mumps and rubella (MMR) vaccines.

From August to November 1998, NSW Health assisted the Commonwealth to carry out the National Enhanced Measles Control Campaign. During this campaign, teams of nurses offered the MMR vaccine to all children in NSW primary schools. The campaign allowed the change in the schedule for MMR vaccination, which was previously given at 12 months and between 10 and 16 years of age.

MMR vaccines should now be given at 12 months of age and before school entry (four to five years of age).

The Australian Immunisation Handbook, 6th Edition, indicates that MMR and oral poliomyelitis vaccine (OPV) may be given simultaneously. For NSW children, the pre-school dose should be recorded on the NSW Health Department Immunisation Certificate for Primary School Entry'. The certificate is being updated; meanwhile, immunisation providers may add a box (on the line for measles) to record the second dose.

Any queries should be directed to your local Public Health Unit.

\section{DrAshwell}

Acting Manager

Immunisation, $A I D B$ 